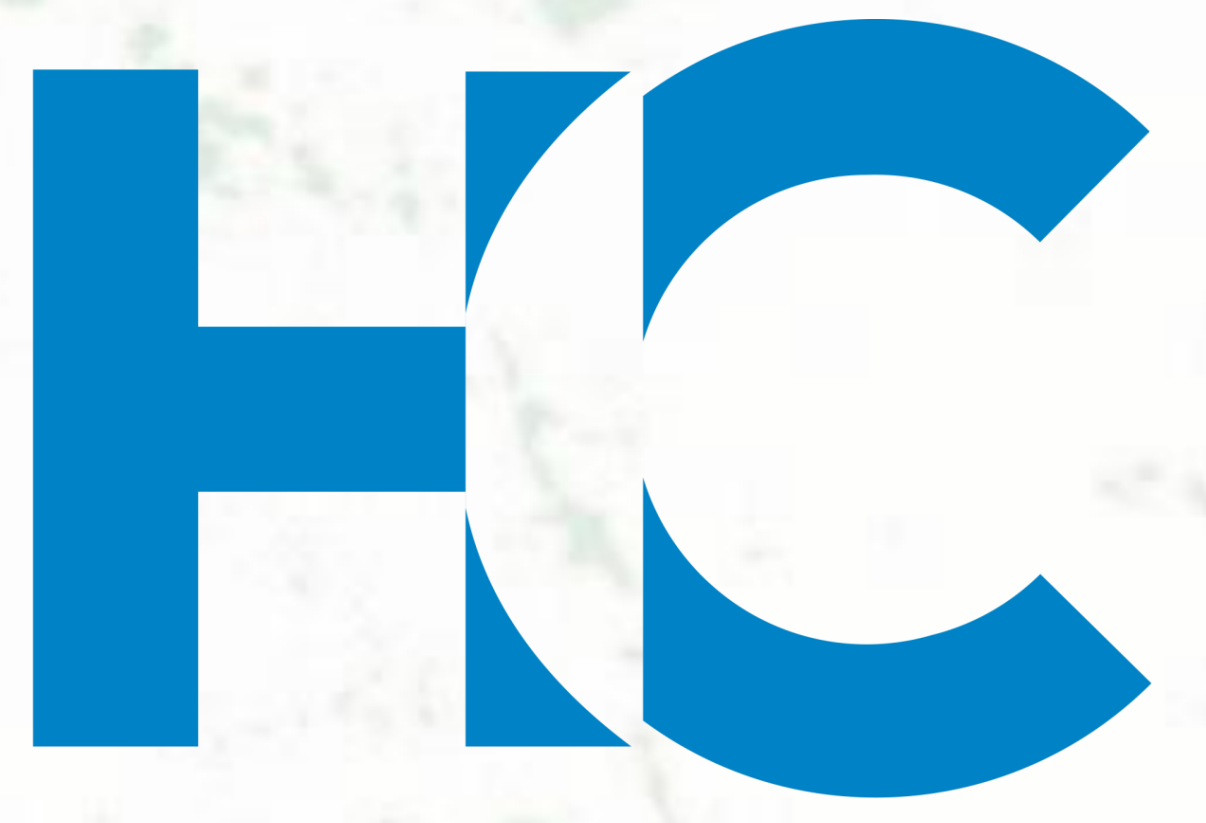

NGP

Núcleo de Gestão de Pessoas

\title{
A importância da Comunicação Interna e do Endomarketing para a Gestão de Pessoas
}

\author{
Comunicar para informar ou para engajar?
}

Jacqueline Quaquarini Galli, Janaína Nascimento dos Santos, José Luis de Lira, Kelly Almeida Lacerda Tabanela

\section{Introdução}

A Comunicação Interna e o Endomarketing nas organizações são indispensáveis para engajar os colaboradores. $O$ grande desafio deste processo educativo é que a comunicação termina no entendimento das pessoas e o engajamento, por sua vez, no comportamento delas em relação ao que foi transmitido.

Por esses motivos, desenvolver um serviço que oferte informações e apresente espaços de inclusão dos colaboradores tem sido cada vez mais utilizado pelas corporações que se preocupam não só em comunicar, mas engajar seus colaboradores.

Com objetivo de ofertar informações direcionadas aos 22.000 (vinte e dois mil) colaboradores, foi implementado um serviço de comunicação interna, responsável pela disseminação de Diretrizes Corporativas, Políticas, Processos de Recursos Humanos e Programas relacionados à Prevenção da Saúde e Qualidade de Vida dos Colaboradores. Que ações foram implementadas a partir desta oportunidade?

\section{Método}

Foi formada uma Comissão de Comunicação Interna, composta por um representante de cada serviço oferecido e estabelecido um cronograma de reuniões mensais para juntos elaborarem uma pesquisa interna com a finalidade de conhecer o públicoalvo: seus hábitos de utilização dos canais internos, e oportunidades de melhorias no formato das comunicações relacionados à Gestão de Pessoas. 1.934 (Hum mil novecentos e trinta e quatro) colaboradores de diferentes áreas responderam à pesquisa; o que impulsionou iniciativas com foco na melhoria da utilização dos canais mais votados e na implementação de novos espaços de inclusão dos colaboradores.

Abaixo um breve resumo do resultado da Pesquisa:
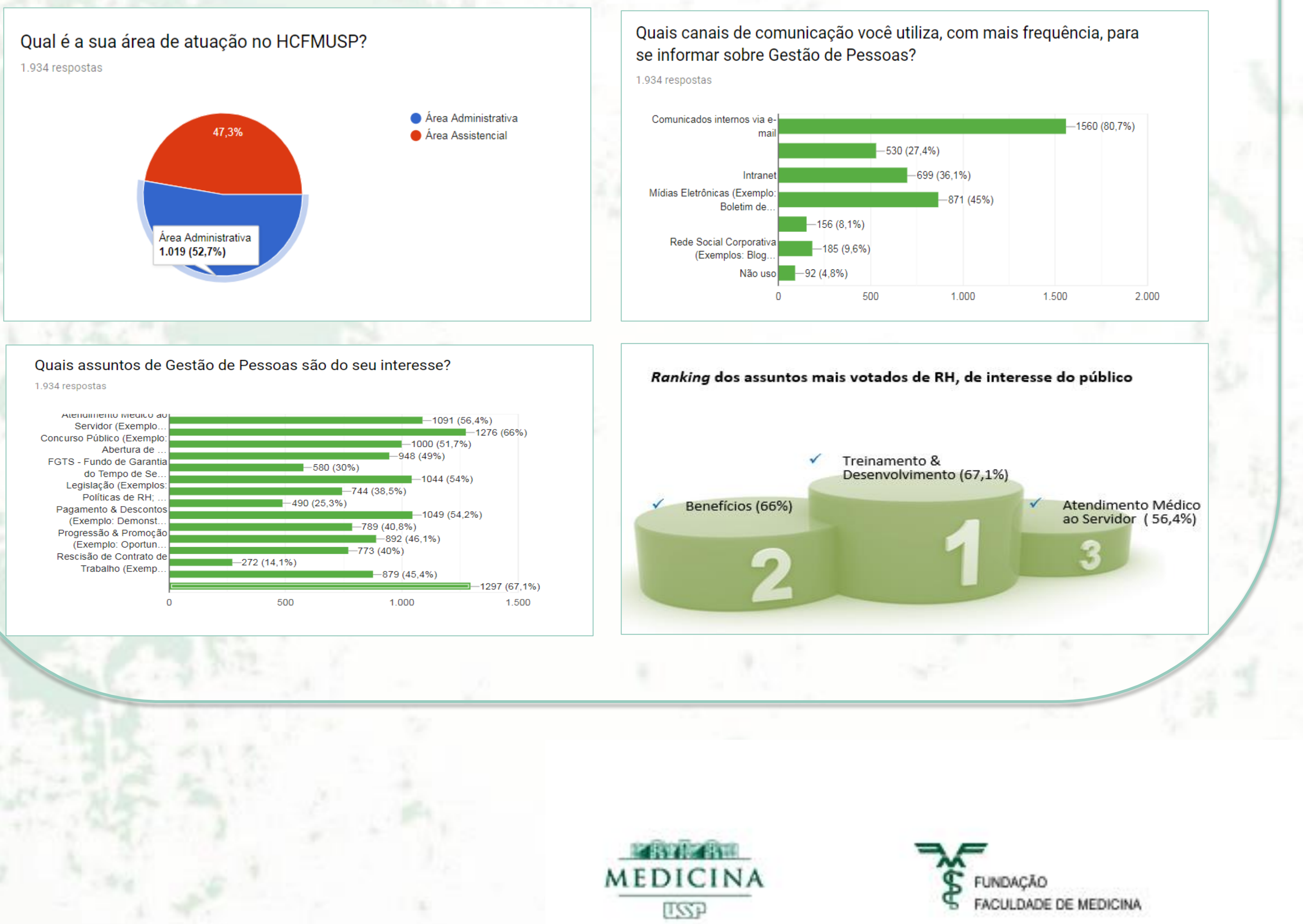

\section{Resultado}

O número de comunicações direcionadas nos diferentes canais de comunicação internos aumentou em $127 \%$, comparando os anos de 2017 e 2018 respectivamente, conforme demonstrado nos gráficos abaixo:
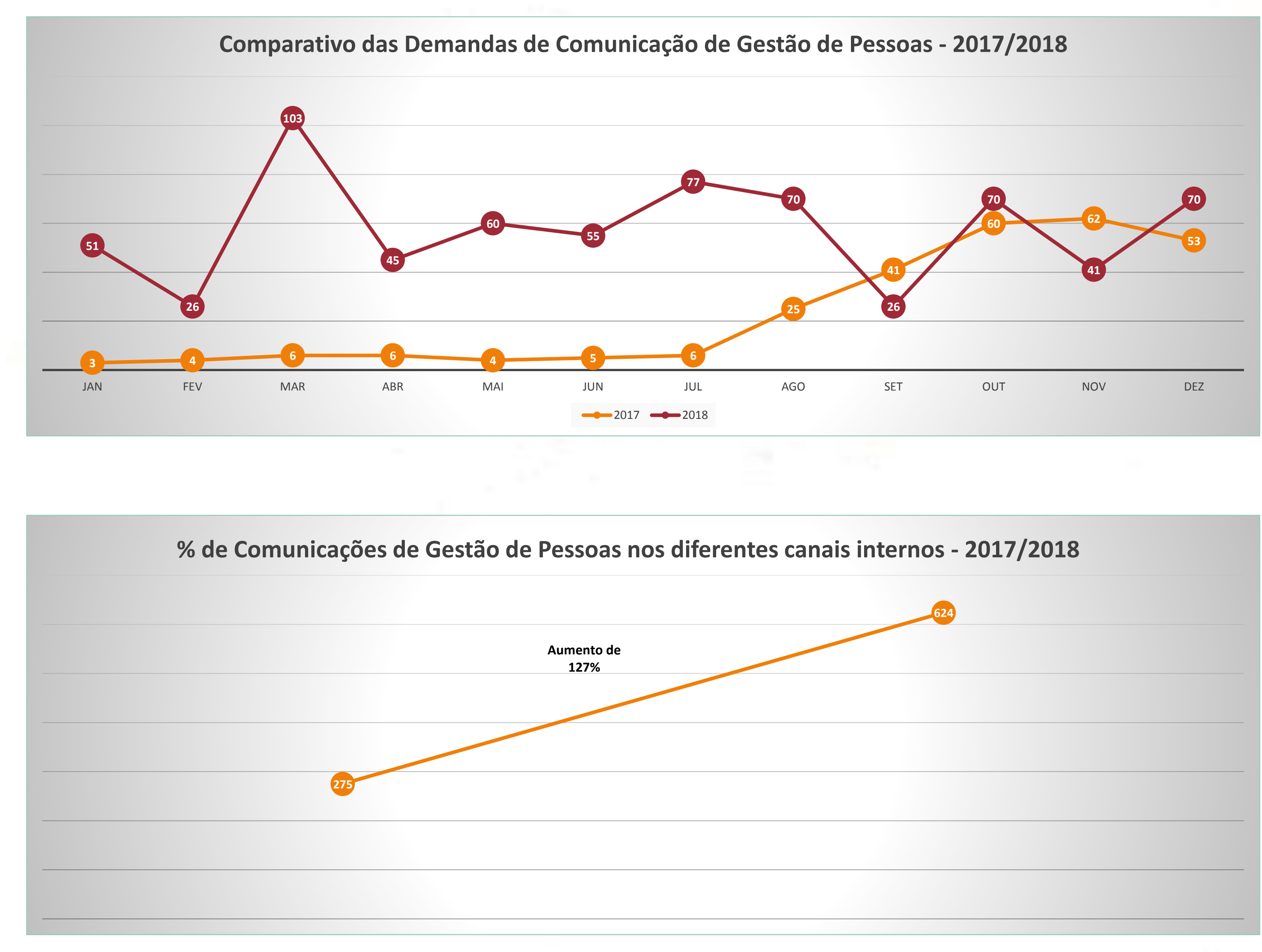

\section{Conclusão}

O envolvimento das pessoas no processo de Comunicação Interna é indispensável para sua efetividade. Se o objetivo é engajar, é necessário conhecimento do público-alvo e dos canais internos que proporcionam maior conectividade com os diferentes públicos.

Para qualificar estas iniciativas e o engajamento dos colaboradores em relação aos assuntos divulgados, está programado para 2019 momentos de interação com o público interno; um dos meios será um Quiz de Gestão de Pessoas, contendo perguntas específicas com premiação e uma nova intranet com conteúdo atrativo e específico de Gestão de Pessoas para ofertar informação, favorecer a transparência dos processos e orientar os diferentes públicos.

\section{Bibliografia}

1. ALMEIDA, Paul Edman de. De Habermas a Poter. In. NASSAR, Paulo. (org.). Comunicação interna a força das empresas. São Paulo: A77, 2005. v. 2.

2. ARGENTI, Paul A. Comunicação Empresarial: a construção da identidade, imagem e reputação. Rio de Janeiro: Elsevier, 2006.

3. CHIAVENATO, Idalberto. Recursos Humanos. Edição Compacta. 7. Ed. São Paulo: Atlas, 2002. 4. 